\title{
MÃE CADEIRANTE: SENTIMENTOS E DESAFIOS EXPERIMENTADOS
}

\author{
WHEELCHAIR \\ CHALLENGES \\ MOTHER: EXPERIENCED FEELINGS \\ $A N D$
}

Michelly Guedes de Oliveira Araújo ${ }^{1}$ Michelinne Oliveira Machado Dutra ${ }^{2}$ Rosilene SantosBaptista ${ }^{3}$

\begin{abstract}
RESUMO: Objetivo: compartilhar os desafios e as experiências vivenciados por uma mulher com deficiência física desde a concepção até a maternidade. Método: trata-se de um estudo de caso, com abordagem qualitativa, realizado durante o período de abril a julho de 2014 em Campina Grande - PB. O sujeito do estudo foi uma mulher com deficiência física, que deu à luz uma criança. A pesquisa foi realizada em três momentos: aplicação de um questionário-piloto, que tratou do perfil da participante; três visitas domiciliares, nas quais as entrevistas foram subdivididas em três categorias e foram realizadas ações educativas a fim de desmistificar possíveis dúvidas. Na análise dos dados, utilizou-se a técnica de análise de conteúdo, de onde emergiram três grandes categorias: mulher com deficiência; gestante com deficiência e mãe com deficiência. Resultados: verificouse uma autoimagem fragilizada e contraditória; episódios em que o preconceito foi vivenciado pela cadeirante; preocupação por não se mostrar atraente para os homens; medo de o filho nascer com deficiência; o filho visto como uma motivação e futuro cuidador. Conclusão: o enfermeiro deve estar apto a encarar situações semelhantes, a prestar uma assistência de qualidade e ter conhecimentos sobre educação em saúde, para que possa auxiliar no processo de inclusão desses indivíduos no meio social. Para isso, é necessário investir em aprimoramento, conhecimento e prática, com o objetivo de promover um atendimento holístico e o bem-estar dessa população com deficiência.
\end{abstract}

Palavras chave: Enfermagem. Gravidez. Pessoas com deficiência.

\footnotetext{
${ }^{1}$ Enfermeira. Doutoranda em Enfermagem pela UPE/UEPB. Docente do curso de Enfermagem do UNIRN.

${ }_{2}^{2}$ Enfermeira. Doutora em Enfermagem pela UPE/UEPB. Docente do curso de Medicina da UNIFACISA.

${ }^{3}$ Enfermeira. Doutora em Enfermagem pela UFC. Docente do curso de Enfermagem da UEPB.
} 
ABSTRACT: Objective: to share the challenges and experiences experienced by a woman with a physical disability from conception to motherhood. Method: this is a case study, with a qualitative approach, carried out from April to July 2014 in Campina Grande - PB. The study subject was a woman with a physical disability, who gave birth to a child. The research was carried out in three moments: application of a pilot questionnaire, which addressed the profile of the participant; three home visits, in which the interviews were subdivided into three categories and educational actions were carried out in order to demystify possible doubts. In the data analysis, the content analysis technique was used, from which three major categories emerged: women with disabilities; disabled pregnant woman and disabled mother. Results: there was a fragile and contradictory self-image; episodes in which prejudice was experienced by the wheelchair user; concern about not being attractive to men; fear of the child being born with a disability; the child seen as a motivation and future caregiver. Conclusion: nurses must be able to face similar situations, to provide quality care and to have knowledge about health education, so that they can assist in the process of including these individuals in the social environment. For this, it is necessary to invest in improvement, knowledge and practice, with the objective of promoting holistic care and the well-being of this population with disabilities.

Keywords: Nursing. Pregnancy. Disabled Persons. 


\section{INTRODUÇÃO}

A maternidade representa um momento único na vida da maior parte das mulheres, permeado por peculiaridades até então não experimentadas. Ter alguma limitação física não significa, necessariamente, abdicar do direito à maternidade, visto que é possível ser uma mãe diferente daquele protótipo "considerado normal", até porque essa população tem uma representatividade expressiva atualmente.

Segundo o Instituto Brasileiro de Geografia e Estatística (IBGE, 2010), o Brasil apresenta $23,9 \%$ da população com algum tipo de deficiência, ou seja, cerca de 45,6 milhões de pessoas. Dentro desse universo, observou-se que $26,5 \%$ da população feminina ( 25,8 milhões) apresentavam, pelo menos, uma deficiência, contra $21,2 \%$ da população masculina (19,8 milhões). Na avaliação por tipo, foi explanado que a deficiência visual ocupa o primeiro lugar, com 35.774 .392 de pessoas; 9.717 .318 apresentavam algum grau de deficiência auditiva; 13.265.599, deficiência motora, e 2.611.536, deficiência mental/intelectual.

Além de o quantitativo ser representativo, observa-se uma mobilização dessa camada populacional, no sentido de reivindicar o que Ihes é garantido por lei. De acordo com a PolíticaNacional para a Integração da Pessoa Portadora de Deficiência inserida no Decreto $n^{\circ} 3.298 / 99$, é assegurado à pessoa com deficiência o pleno exercício de direito à educação, à saúde, ao lazer, à cultura, ao amparo à infância e à maternidade, entre outros benefícios (BRASIL, 1999). Entretanto, apesar de ser garantido por lei, nem sempre o exercício desses direitos acontece de forma plena, como o direito à maternidade, por exemplo. Em nosso meio, a maternidade é vista como algo positivo e socialmente valorizado. Ser mãe reflete mais prestígio na sociedade, ou seja, representa a potencialidade máxima da trajetória do feminino (RANGEL; QUEIROZ, 2008). Assim, mulheres com deficiência também vislumbram usufruir dessa condição natural. Estudos apontam, todavia, que mulheres com deficiência são enfaticamente marcadas, devido ao processo histórico de infantilização e dependência familiar em que estão sujeitas,onde as características 
de fragilidade feminina são mais acentuadas (DANTAS; SILVA; CARVALHO, 2014).

Mulheres com deficiência são visualizadas como seres dependentes, assexuadas e excluídas de desempenhar papéis tradicionalmente femininos, inclusive têm sido desestimuladas ou até excluídas da oportunidade de gerar e criar filhos (PRILLELTENSKY, 2003, p. 22). Segundo Jeffreys (2008), as mulheres com deficiência carregam algumas desvantagens, a saber: a discriminação de gênero, a deficiência em si e, frequentemente, a exclusão social. Assim, mitos e tabus são perpetuados, e isso dificulta sua desconstrução e a conscientização dessas mulheres, para que tenham acesso ao conhecimento e possam vivenciarplenamente a maternidade.

Diante da problemática abordada, pretendeu-se, com este estudo, buscar respostas para os seguintes questionamentos: Existem mitos ou tabus relativos à mulher com deficiência que a impeçam de gerar um filho? Que dificuldades e desafios surgiram antes, durante e depois do período da gestação? Quais as expectativas dessa mãe em relação à gravidez e ao filho? Na perspectiva de que o enfermeiro atua na promoção do cuidado, no preparo de ações educativas voltadas para a população, este configura-se como uma ferramenta importante para desmistificar mitos e tabus que possam interferir no exercício de ser mãe com deficiência física.

\section{MÉTODO}

Trata-se de um estudo de caso com abordagem qualitativa e integrativa, que foi realizado no período de abril a julho de 2014, na cidade de Campina Grande, PB. A pesquisa foi realizadano domicílio da participante, por se tratar de uma cadeirante, o que traria mais conforto para a entrevistada. O sujeito alvo da pesquisa foi uma mulher cadeirante, que deu à luz uma criança, selecionada para participar da pesquisa porque atendeu aos seguintes critérios de inclusão: ter idade igual ou superior a 18 anos, ser mãe cadeirante e concordar em participar da pesquisa. 
Para o desenvolvimento da pesquisa, o instrumento de coleta de dados mais adequado foi a entrevista semiestruturada, que foi realizada com a utilização autorizada de gravador e agendada por meio de contato direto, de acordo com a disponibilidade da participante.

A pesquisa foi realizada em três momentos: no primeiro, foi aplicado um questionário- piloto, que tratou do perfil da participante e averiguou se alguma pergunta elaborada no questionário não estava adequada. No segundo, realizaramse três visitas domiciliares, e as entrevistas foram subdivididas em três categorias: mulher com deficiência; gestante com deficiência e mãe com deficiência. Nesse momento, solicitou-se da participante permissão paragravar as entrevistas, para que fosse possível discutir os dados com mais fidedignidade. E por fim, após a exposição das inquietações advindas da mulher, foram realizadas ações educativas a fim de desmistificar possíveis dúvidas.

A análise e a discussão das informações foram feitas através da categorização do material coletado durante a realização do questionário, com base na análise de conteúdo e respaldo da literatura pertinente, fundamentada nos conceitos de promoção da saúde. Para Bardin (2009), a análise de conteúdo, como método, é um conjunto de técnicas de análise das comunicações em que se empregam procedimentos sistemáticos e objetivos de descrição do conteúdo das mensagens.

O estudo foi submetido ao Comitê de Ética em Pesquisa da Universidade Estadual da Paraíba e aprovado sob $n^{\circ} 30385514.3 .0000 .5187$, para garantir os princípios éticos, liberdade de participação e de abandono do estudo, beneficência, não maleficência, sigilo sobre a identidade do sujeito e utilização dos dados do estudo exclusivamente para a pesquisa.

A participante foi esclarecida sobre os objetivos e os benefícios da pesquisa e teve assegurados o sigilo, a privacidade e o direito de desistir, em qualquer momento, de participar da investigação, sem qualquer tipo de ônus. Foi apresentado o Termo de Consentimento Livree Esclarecido e, em seguida, assinado o Termo de Consentimento Pós-esclarecido, conforme preconiza a Resolução 466/12 do Conselho Nacional de Saúde (BRASIL, 2012). 


\section{RESULTADOS}

A participante havia cursado o ensino fundamental incompleto, tinha 37 anos, casada ea sua deficiência física se deu devido à paralisia infantil na infância, quando tinha seis anos de idade. Desde então, é cadeirante. Porém, apesar da limitação física, realiza na cadeira todas astarefas domésticas.

De acordo com os resultados obtidos nas entrevistas, emergiram três grandes categorias: 1. Mulher com deficiência (de onde surgiram as subcategorias 'autoimagem' e 'conflitos pessoais'); 2.Gestante com deficiência (que teve como subcategoria a 'relação homem-mulher') e 3. Mãe com deficiência (como subcategorias: 'família'; 'filho como motivação para o futuro' e 'relacionamento profissional/parto').

\section{Mulher com deficiência}

Essa categoria apresentou as seguintes subcategorias: autoimagem e conflitos pessoais.

\subsection{Autoimagem}

A forma como cada indivíduo se enxerga compõe a sua autoimagem. Essa é construída continuamente, através de momentos vivenciados ao longo da vida, sentimentos experimentados, troca de experiências com pessoas que passam por seu convívio. Assim, Amorim et al. (2021) traz que a auto imagem é uma representação do indivíduo sobre seu corpo e mente. E com os aprendizados adquiridos, essa imagem é passível de frequentes mudanças. 
Santos e Hoepers (2019) afirmam que a percepção de si é originada a partir das vitóriasalcançadas e que estas são influenciadas pela família e amigos, mas se percebe fisicamente deficiente. De acordo com os achados da pesquisa, observa-se um conflito no que diz respeito à autoimagem, como exposto:

[...] Como qualquer outra mulher, eu nunca me vi diferente de mulher alguma. Às vezes, quando eu era mais jovem, eu me vi assim né, eu era mais problemática, me via diferente, né [...]

Nessa fala, a entrevistada afirma que nunca se enxergou como diferente das demais mulheres sem deficiência. Entretanto, logo em seguida, contradiz-se, justificando essa percepção antagônica por causa da adolescência. Esse período é encarado como uma fase marcada por transformações corporais e hormonais, que exercem influência sobre o estado emocional do adolescente. Para Kroeff (2012), a adolescência pode ser sensível, mas, para pessoas com deficiência, esse período pode ser mais complicado, pois as dificuldades tornam- se mais pontuais, ao verem, por exemplo, seus irmãos evoluindo nos estudos, na vida profissional e na amorosa. Isso causa tensão, desconforto emocional e, até descrença em seu potencial.

Mas uma vez, a entrevistada remete essa percepção inferiorizada de si mesma à fase da adolescência, à imaturidade, através da fala a seguir. Entretanto, apresenta, mais uma vez, a contradição de não se achar diferente.

[...] Depois dos meus vinte anos, por aí, vinte, vinte e poucos anos, aí minha mente já foi mudando e sinceramente não me via e não me vejo, nunca me vi diferente de mulher alguma [...]

No decorrer das falas, foi possível visualizar a fragilidade da autoimagem apresentada pela entrevistada, revelando sua baixa autoestima, pois ela declara, inicialmente, que é tímida, contudo, chega à conclusão de que sentia vergonha de si mesma, de sua condição física. O estudo de Maia et al. (2020) reforça o estigma 
englobado pela "diferença" nessa população, a qual não cumpre os padrões instituídos de beleza, perfeição e simetria. Isso é evidenciado nestetrecho:

\section{[...] Eu que era envergonhada, eu era muito envergonhada no começo, porque eu tinha vergonha de mim mesma [...]}

Tratando da autoimagem, que é uma preocupação que rege os indivíduos, pois a aparência é uma das exigências que vigoram na sociedade para se incluir em um grupo social, essa é uma questão peculiar para as pessoas com deficiência que, de acordo com Buscaglia (2006), preocupam-se em ser desinteressantes, devido a uma cadeira de rodas, a alguma prótese e a problemas na fala, pois esses fatores podem resultar em rejeição. Isso é visto na fala a seguir, em que a entrevistada explana que seu estereótipo não atraía os homens, mas quando eles ultrapassavam a barreira do que viam, tinham a oportunidade de conhecer uma pessoa passívelde despertar interesse.

[...] Porque a partir do momento que eles me conheciam, aí eles viam que o meu corpinho não chamava atenção, mas eu em si chamava [...]

Com a maternidade, a entrevistada apresentou sua autoestima mais revigorada e demonstrou que, com o nascimento do filho, encorajou-se para enfrentar a vida e seusobstáculos sob outra ótica, fazendo-se mais forte diante das situações que estivessem por vir, conforme a fala a seguir:

[...] Então como mãe, como mulher, eu me considero forte/...eu me considero forte ainda, me considero forte e me considero umalutadora [...]

Observa-se, pois, que a autoimagem é uma condição em que a sociedade é um ponto importante nessa aceitação ou não da limitação física, e os que promovem 
saúde, como os enfermeiros, são peças fundamentais nesse processo de reconstrução de conceitos e quebra de barreiras através da educação em saúde, na perspectiva de minimizar os conflitos que porventura possam advir.

\subsection{Conflitos pessoais}

Independentemente de ter ou não algum tipo de deficiência, o ser humano é regido porsentimentos e emoções que, na maioria das vezes, são mais enfáticos do que em pessoas sem deficiência. Isso pode ser decorrente de alguns fatores, como os estigmas e os tabus implantados nesses indivíduos, os preconceitos sofridos, as limitações e as dificuldades vivenciadas que, somadas, resultam em sofrimento emocional, depreciação das capacidades e outras sensações.

$\mathrm{Na}$ fala seguinte, é possível visualizar a insegurança quanto ao seu desempenho e à concretização das relações amorosas. Essa hesitação é fortemente influenciada pelas pessoas que fazem parte do seu convívio, onde, devido ao preconceito, esses sujeitos fazem com que a pessoa com deficiência internalize a ideia de não poder efetivar suas relações como os demais.

[...] Assim, sei lá se ia dá certo, se eu ia conseguir, se eu ia namorar, se eles iam gostar. Eu tinha muitas dúvidas com isso./ Então, pronto, isso às vezes me deixava triste, porque as dúvidas das pessoas entravampra mim também. / “... eu mostrar as minhas amigas que eu podia ter o meu filho, de eu mostrar a todo mundo que eu era igual, que eu podia engravidar. Porque muitas pessoas me perguntavam: "será que tu vai ter? E será que tu vai poder?[...]

Corroborando a citação anterior da entrevistada, Dantas, Silva e Carvalho (2014) afirmam que os indivíduos no geral reagem com espanto, quando se aborda 
a sexualidade de mulheres com deficiência, pois estas são vistas como pessoas fragilizadas e apontadas como vítimas de abuso sexual mesmo quando a relação é permitida e desejada. O preconceito não permite fazê-los enxergar que essas pessoas têm capacidade de se relacionar, de sentir atração por alguém, de formar uma família.

Um dos sentimentos mais vivenciados por essa população é o medo, presente nas mais variadas situações, dentre elas, da possibilidade de engravidar. Nesse caso, alimentadas pela falta de informação, as pessoas com deficiência e os que as cercam nutrem a ideia de impossibilidade de gerar um filho devido à deficiência instalada. Nessa perspectiva, Dantas, Silva e Carvalho (2014) concordam que esse estigma de que pessoas com deficiência não têm sexualidade acarreta outros grandes equívocos, dentre eles, lidar com o senso comum sobre a possibilidade ou não de ter filhos. Na fala abaixo, fica exacerbado o medo referido:

[...] Primeiro, eu tinha medo, sei lá. Eu achava que não podia ter, se ia poder engravidar./ Será que eu vou conseguir ter um bebê? Um sonhoque achava que não ia conseguir, mas consegui! / Medo de não conseguir segurar a gravidez, de como é que eu ia ficar com o barrigão sentada nessa cadeira, medo de dá a hora do parto, como será que eu vou ter? / ... às vezes de medo, de insegurança, como é que ia ser o meuparto, se eu ia aguentar $[\ldots]$

Além disso, por vivenciar a experiência de ser mãe com deficiência e por experimentar todas as dificuldades, preconceitos e tantos outros incômodos, pode haver o desencadeamento de outra preocupação: o nascimento de um filho com deficiência. Assim, a expectativa de ter uma criança com deficiência causa um desequilíbrio na família, pois estamos subjulgados a um paradigma de normalidade (SANTOS, HOEPERS, 2019). Na fala seguinte, a mãe traz explicitamente a preocupação de o filho nascer com alguma deficiência. 
[...] Nossa! Eu tinha medo dele nascer com alguma deficiência, por mais que alguém dissesse: Não vai, não tem perigo. Mas eu ainda ficava matutando aqui no meu juízo... Todas as ultrassons mostravam que ele tava normal, mas eu imaginava o dia dele nascer pra eu vê mesmo que ele tava perfeito[...]

Somando-se aos mitos já citados aqui, as mulheres com deficiência também são confrontadas sobre sua capacidade de cuidar dos filhos. Dantas, Silva e Carvalho (2014) concordam ao afirmar que mulheres com deficiência são julgadas como incapazes de constituiruma família e cuidar dos filhos, como expressa esta fala da entrevistada:

[...] Eu tinha medo de como será que vai ser pra criar, pra cuidar. Seráque eu vou conseguir cuidar como as outras mães? / Eu comecei dando a mamadeirinha a ele, mas eu fiquei com tanto medo, sem saber cuidar dele, que eu passei a noite inteira sem dormir [...]

Ela também apresentou um bloqueio com a possibilidade de uma gestação futura. Esse entrave detém uma conotação firme e não deixa espaços para repensar em outra gravidez, comomostra nesta sua fala:

[...] Fiquei com medo de botar minha vida em risco, botar a vida de outro bebê em risco, fiquei com medo de passar por tudo que eu passei, fiquei com medo de sustentar outra barriga. Com medo, Nossa! Eu não quero ter outro filho. Eu acho que não tenho capacidade de cuidar de outra criança, por causa do cansaço, do meu filho também, são muitasdificuldades [...]. 
Com a descoberta da morte da avó, o sofrimento causado pela perda resultou em complicações na reta final da gravidez e em um substancial abalo emocional. Andrade et al. (2021) reforça essa percepção ao abordar a morte como um momento permeado por sofrimentoadvindo da saudade pela perda dos que partiram. No relato a seguir, a entrevistada demonstra ter experimentado profundo padecimento, que a levou a culpar o próprio filho por ter permanecido no hospital, o que a impediu de ir ao velório. Esse acontecimento marcou-a intensamente e, junto com o descontrole emocional, culminou em um novo sentimento: o de revolta contra o filho. Segue o trecho:

[...] Pra mim, nada que tava ali importava. Eu me revoltei com meu filho, que é o maior amor da minha vida. Dizia que a culpa era dele que eu tava ali... Coisa que, sinceramente, hoje eu não entendo porque eu fiz tudo aquilo. Então sinceramente eu só pensava na dor que eu tava de ter perdido ela, eu não queria saber de mais nada[...].

Depois, passado o choque acarretado pela perda abrupta, a pesquisada passou a refletirsobre suas condutas e pensamentos, o que gerou um sentimento de culpa. Isso aconteceu com mais vigor ao ver o filho pela primeira vez, com fragilidades, o que fomentou nessa mãe a responsabilidade pelo fato.

[...] Eu me debrucei por cima da incubadora, porque eu senti muita culpa, porque ele não tava bem. Sabe, tava respirando com tanta dificuldade, por conta da parada que ele tinha tido. Eu disse: Meu Deus do céu! Eu pedi tanto perdão a Deus, que Deus salvasse ele, me perdoasse por tudo que eu tinha feito, que ele não tinha ficado mais na minha barriga por culpa minha, que ele tava ali daquele jeito, podia morrer, por culpa minha. Na verdade a primeira vez que eu senti ele, eu só senti culpa [...]. 


\section{GESTANTE COM DEFICIÊNCIA}

Essa categoria teve como subcategoria a 'relação homem/mulher'.

\subsection{Relação homem/mulher}

$\mathrm{Na}$ fala seguinte, a entrevistada expõe sua preocupação com a supervalorização docorpo, que a sociedade impõe através de padrões traçados, como a magreza ideal, o cabelo perfeito, não ter celulites, estrias, entre outros estereótipos endeusados por homens e mulheres.

[...] Os homens hoje visam muito à beleza, o "corpinho bonitinho".

Então eu sabia que não ia ser fácil [...].

Para o sujeito sem deficiência se incluir no grupo de pessoas consideradas atraentes, já representa um esforço considerável a fim de atingir os modelos de beleza idealizados. Para a pessoa com deficiência chegar a esse patamar, é necessário mais esforço, ou até mesmo encarar essa possibilidade como inalcançável.

Mesmo com algumas concepções arcaicas de que pessoas com deficiência não apresentam meios de exercer sua sexualidade com plenitude, Bittencourt (2014) reforça que a deficiência não implica na impossibilidade de exercer sua sexualidade, esta é pautada em um conceitoamplo. Porém, o preconceito permanece arraigado no relacionamento entre uma pessoa com deficiência e outra sem. Mesmo assim, a entrevistada apresenta uma união bem sucedida com seu parceiro sem deficiência.

Ressalte-se, entretanto, que, durante a gestação, houve mudanças na vida a dois. Conforme a fala abaixo, nesse período, a entrevistada não apresentou 
interesse sexual pelo marido. Esse afastamento pode causar conflitos entre os dois e dificultar a rotina da casa e a cumplicidade existente, pois a vida sexual é um fator importante para a coexistência do casal.

[...] Atrapalhou muito no começo, eu não queria nada. Acho que eu enjoei dele. Eu tinha pavor até do cheiro dele, quando ele chegava perto de mim, eu ficava agoniada. Acho que praticamente a gravidez inteira, foi muito difícil acontecer alguma coisa, porque atrapalhou bastante. Dava um abuso [...]

Com o nascimento do filho, surgiram outras tarefas e, com isso, uma sobrecarga. Emseu discurso, ela alega um cansaço excessivo, que a impedia de exercer o papel de mulher na relação, o que enfraqueceu a intimidade do casal. Essa assertiva está expressa na fala a seguir:

[...] Na medida do possível, normal, né?! Por conta do bebê, às vezes esfriou um pouco nossa relação, porque eu fico muito cansada cuidando do meu filho, de casa, de roupa, de tudo. Às vezes, de noite, muitas vezes, eu tô tão cansada que sinceramente eu não consigo ser mulher pra o meu marido. Muitas vezes, ele já veio me procurar e eu não quis nada com ele. Então eu só quero dormir [...]

Com a chegada do bebê, há uma série de modificações na rotina desempenhada pela mãe e pelo pai, tanto nos serviços domésticos e de cuidados com o filho quanto na vida sexual dos dois. Kroeff (2012) alega que essas adaptações não são vistas como uma crise, pois é umafase natural da vida, em que cada casal deve operar, de forma aceitável, recebendo também o apoio de familiares. Na fala abaixo, é explicitada a situação abordada: 
[...] Mas quando eu tenho uma chance de tá menos cansada a nossa relação chega a ser normal e tudo. A convivência, como diz, a convivência mudou né?! Porque agora a gente não é mais dois, a gente é três. Mas ele é um bom pai, é um ótimo pai, ele me ajuda a cuidar domeu filho desde pequenininho. Na medida desse possível é normal $[\ldots]$.

\section{MÃE COM DEFICIÊNCIA}

Essa categoria subdividiu-se nas subcategorias: 'família', 'filho como motivação do futuro' e 'relacionamento profissional/parto'.

\subsection{Família}

A mãe cadeirante expressa, através da sua fala abaixo, a concretização da ideia de que depende da figura materna. Nela, está ancorada toda a segurança, o respaldo e a capacidade dedar o devido suporte ao neto.

[...] 7h da manhã, eu sozinha, sem minha mãe, sem minhas tias, sem minha irmã. Eu parei, eu disse: Jesus, o que é que eu faço? "Então, quem me ajudou foi minha vizinha, que eu chamei ela pra ir comigo buscar o bebê, porque o sonho era trazer ele com a minha mãe do hospital ela não tava nem nesse momento. / Quando eu cheguei lá, nem arrumar ele eu sabia, eu pensava que minha mãe estava comigo [...] 
Essa mãe com deficiência transmite, em suas falas, o valor que atribui à sua família, porquanto a vê como base para a vida e almeja o mesmo parâmetro para seu filho. Assim, Santose Hoepers (2019) abordou em seu estudo que a família é a base fundamental e estabelece vínculos afetivos que determinam suas primeiras experiências de acolhimento e relação interpessoal, que possui valores e princípios, os quais são transmitidos entre gerações.

[...] Eu vejo minha família, como dizem, é o alicerce, é a estrutura da minha vida, da minha educação. É a estrutura que eu quero passar promeu filho [...].

\subsection{Filho como motivação para o futuro}

Um filho renova a dinâmica de uma família e, nesse quadro, ele exerceu sobre essa mãe um papel fortalecedor, que a ergueu, possibilitando o vislumbre de um futuro, regido por planos e carregado de esperanças em função dele. Ele foi o responsável por dar fôlego a essa cadeirante para que ela achasse sentido para seguir adiante. Isso pode ser comprovado no trecho seguinte:

[...] Alegria de viver, vontade de continuar, de ir em frente, vontade de pensar no meu futuro, no futuro dele. / $\mathrm{Na}$ verdade ele foi a luz pra mim, depois de tanta dor e de tanto sofrimento, o sorriso dele e o cheirinho foram coisas que me fizeram sorrir, que me fizeram felizes nesse momento difícil. Então ele foi a luz da minha vida [...].

No trecho abaixo, a entrevistada explicita que o filho também representa uma esperança, pois ela o vê como um cuidador futuro, que lhe dará tranquilidade e perspectivas de vivenciar a velhice. Contudo, mais uma vez, o marido não é 
considerado como família, como cuidador, ele exerce um papel coadjuvante no seio familiar.

[...] O que ele acrescentou foi esperança, esperança de eu ter uma velhice, de eu ter ele comigo na minha velhice pra cuidar de mim, de ter quem cuide de mim, de ter uma família no futuro [...].

\subsection{Relacionamento profissional/ parto}

O enfermeiro exerce um papel primordial na assistência, porquanto the é concedido o exercício do cuidado, que é mais peculiar quando se trata de pessoas com deficiência. Conforme Araújo et al. (2018) é primordial a sensibilização do profissional de saúde em relação às pessoas com deficiência. O cuidado deve ser planejado com base em diversas ações para promover umaassistência integral.

Segundo o relato da entrevistada, a atenção concedida pelos enfermeiros foi satisfatória, pois a maioria dos profissionais mostrou-se comprometida e habilitada para o desempenho das ações voltadas para pessoas com deficiência. Além disso, proporcionaram o apoio emocional e a afeição, que são marcantes no discurso. Em concordância, Aragão (2010) afirma que o afeto existente, principalmente, entre profissionais de saúde e as pessoas mais íntimas é bastante significativo.

[...] Graças a Deus os enfermeiros foram atenciosos, não sei se por conta da deficiência eles me trataram assim. Foi tudo bem, davam força, tinham paciência, conversavam, davam apoio, palavras de carinho. / No posto tiravam minhas dúvidas, cuidavam de mim, todos tratam muito bem. Me acompanharam direitinho, cuidando [...]. 
Conforme o trecho acima, o serviço prestado pelos enfermeiros nas estratégias de saúde da família também foi realizado de forma adequada, porque eles atuam na promoção da saúde, através de informações e acompanhamento. Nesse aspecto, o enfermeiro deve atuar através de atividades de educação em saúde, ações e comportamentos inclusivos para construir espaços acessíveis e propiciar um meio favoráveis à promoção da saúde para essa população (ARAÚJO et al., 2018).

No tocante às dificuldades mencionadas na entrevista, uma das maiores, relatada pela cadeirante, foi em relação ao seu parto, conforme o trecho abaixo:

[...] a maior dificuldade que eu tive foi na hora do parto. Eu acho que por conta da deficiência o que mais atrapalhou, por conta do meu corpo, porque eu não consegui ser anestesiada, a anestesia não pegou por causa da minha coluna, que por conta da deficiência minha colunaé torta. I Porque eu não pude ter um parto normal, já por conta da deficiência e nem uma cesariana normal quase eu não podia tertambém porque não pegava nada...Me furaram 10 vezes e a anestesia não pegava na minha coluna [...]

Diante do relato, ficou evidente o sofrimento causado a essa mulher durante a analgesia. Isso evidencia a incapacidade e o despreparo dos profissionais para lidarem com mulheres grávidas com deficiência. Somando-se a esse aspecto, Meekosha e Frohmader (2010) complementam afirmando que outro grande obstáculo é a falta de equipamentos adaptados que sejam adequados para prover suporte às mulheres com deficiência. Também é demonstrado negligência no pósparto, pois, no local da incisão cirúrgica, houve infecção, e a cadeirante não teve o acompanhamento necessário, segundo o relato abaixo:

[...] Teve dificuldade porque eu toda ponteada, sentada na cadeira derodas, meus pontos começaram até a inflamar, chegaram até a feder. 
Essa fala demonstra que a assistência puerperal deixou a desejar, haja vista que, como cadeirante, essa mulher precisaria de cuidados específicos, no sentido de erradicar eventuais infecções.

\section{CONCLUSÃO}

Este estudo revelou diversas vivências de uma mulher cadeirante, antes da gestação, durante esse período e depois, perpassando seus sentimentos, conflitos, dificuldades, relações interpessoais, entre outros aspectos. Diante da análise geral dos dados, constatou-se que, mesmocom todo o respaldo alcançado com as leis que protegem e regem os direitos de pessoas com deficiência, atrelado a estudos em ascensão que tratam dessa temática, essa população continua sendo encarada com desigualdade.

Desse modo, a abordagem do estudo é de grande valia, pois viabilizou um olhar aprofundado no que tange as fragilidades da autoimagem do sujeito da pesquisa, o medo que norteou a gestação, pois, nesse período, sempre esteve presente nessa mãe a possibilidade de que seu filho nasceria com deficiência. Além da percepção de que o filho passaria a desempenhar um papel fundamental na vida dessa mulher, seu futuro cuidador. As dificuldades também estiveram presentes ao longo da análise, contudo o sofrimento enfrentado no momento do parto mostrou-se substancial para a cadeirante, pois ela se compara com mulheres sem deficiência e conclui que tudo o que passou foi gerado pela deficiência.

Portanto, a ausência de uma assistência capacitada e adaptada para essa gestante, com profissionais preparados para lidar tanto com a gestação quanto com a deficiência, resultou em uma experiência negativa para essa mulher. O que enfatiza a necessidade de aperfeiçoamento profissional para assim alcançar uma assistência adequada.

Nesse sentido, o enfermeiro deve estar apto a encarar situações semelhantes, a prestar uma assistência de boa qualidade e ter conhecimentos sobre 
educação em saúde, para que possa auxiliar no processo de inclusão desses indivíduos no meio social, para que possam exercer sua cidadania. Para isso, é necessário investir na equipe multiprofissional, com aprimoramento, conhecimento e prática, com o objetivo de promover um atendimento holístico e o bem-estar dessa população com deficiência.

\section{REFERÊNCIAS BIBLIOGRÁFICAS}

AMORIM, M.L.C., PONCE, K.B., LOPES, K.A.T., MICHILES, R.K.S., JÚNIOR, P.M.M., HARA, Y.B. A imagem corporal de indivíduos com lesão medular participantes de um programa de reabilitação. Educação Física e Ciências do Esporte Uma Abordagem Interdisciplinar. V. 2, 2021.

ANDRADE, P.C.S.T., GOMES, A.M.T., SPEZANI, R.S., NOGUEIRA, V.P.F., BARBOSA, D.J., BERNARDES, M.M.R., PEIXOTO, A.R.S. Representação social da morte para estudantes de enfermagem. Cogitare enferm. V. 26, 2021.

ARAGÃO, A.E.A. Estratégias de empoderamento de pessoas com deficiência física para reivindicar espaços hospitalares acessíveis. Tese (Doutorado em Enfermagem) - Faculdade de Farmácia, Odontologia e Enfermagem, Universidade Federal do Ceará, 2010.

ARAÚJO, L.M., ARAÚJO, A.E., PONTE, K.M.A., VASCONCELOS, L.C.A. Disabled people and types of barriers to the accessibility of health services - integrative review. Rev Fund CareOnline. V. 10, n. 2, p. 549-557, 2018.

BARDIN, L. Análise de Conteúdo. Lisboa, Portugal; Edições 70, LDA, 2009.

BITTENCOURT, J.R. Inclusão e sexualidade: na voz de pessoas com deficiência física. Revista feminismos. V. 2, n. 1, 2014.

BRASIL. Conselho Nacional de Saúde. Resolução n 466, de 12 de dezembro de 2012. Dispõe sobre diretrizes e normas regulamentadoras de pesquisas envolvendo seres humanos. Diário Oficial da União: seção 1, Brasília, DF, ano 150, n. 112, p. 59-62, 13 jun. 2013.

BRASIL. Decreto no 3.298, de 20 de dezembro de 1999. Dispõe sobre a Política Nacional paraa Integração da Pessoa Portadora de deficiência. Diário Oficial da República Federativa do Brasil. Seção 1, p. 10, 21 de dez. 1999.

BUSCAGLIA, L. Os deficientes e seus pais. Editora Record. 5a Edição. Rio de Janeiro, 2006. DANTAS, T.C, SILVA, J.S.S., CARVALHO, M.E.P. Entrelace entre gênero, sexualidade e deficiência: uma história feminina de rupturas e empoderamento. Rev. bras. educ. espec. V.20, n. 4, 2014.

IBGE. INSTITUTO BRASILEIRO DE GEOGRAFIA E ESTATÍSTICA. Dia Internacional das Pessoas com Deficiência. 2010. Disponível em: http://censo2010.ibge.gov.br/noticiascenso?id=1\&idnoticia=2170\&view=noticia.

JEFFREYS, S. Disability and the male sex right. Womens Stud. Int. Forum. V. 31, p. 327-335, 2008. 
KROEFF, P. A pessoa com deficiência e o sistema familiar. Revista Brasileira de Terapia de Família. V. 4, n. 1, p. 67-84, 2012.

MAIA, A.C.B. A importância das relações familiares para a sexualidade e a autoestima de pessoas com deficiência física. Psicologia.com.pt. V. 1, 2010.

MAIA, A.C.B., VENTURIN, A.B., LONGHITANO, B., LEITE, M.G.R., GRAVALOS, N.M. Padrões de beleza, feminilidade e conjugalidade em princesas da disney: uma análise de contingências. Revista diversidade e educação. V. 8, p. 123-142, 2020.

MEEKOSHA, H., FROHMADER, C. Recognition, respect and rights: disabled women in a globalised world. Paper presented to the 2010 Regional Conference on Women with Disabilities Guangzhou on behalf of Women With Disabilities Australia (WWDA), 2010.

PRILLELTENSKY, O. A ramp to motherhood: the experince of mothers with physicaldisabilities. Sexuality and Disability. V. 21, n. 1, p. $21-47,2003$.

RANGEL, D.L.O., QUEIROZ, A.B.A. A representação social das adolescentes sobre a gravidez nessa etapa da vida. Esc Anna Nery Rev Enferm. V. 12, n. 4, p. 780-88, 2008.

SANTOS, A.M.C., HOEPERS, I.S. A inserção social de uma pessoa com deficiência física: um estudo de caso. As Ciências Humanas e a Produção Criativa Humana. V. 2. Atena editora, 2019. 